\title{
Effects of lipid-lowering agents on plasma lipid profile and apolipoprotein $B$ in patients with type 2 diabetes mellitus
}

\author{
Idowu, A.O. ${ }^{1,2}$, Ebesunun, M.O. ${ }^{3}$, Adekoya, A.O..$^{2,4}$, Taiwo, F. ${ }^{1,2}$, Adesegun, O.A. ${ }^{1}$, \\ Idowu, A.A. ${ }^{5}$, Uka, A. ${ }^{1}$, Amusan, O.O. ${ }^{1}$, Ehioghae, O. ${ }^{1}$, Amballi, A.A. ${ }^{3}$
}

\begin{abstract}
Objectives: Type 2 Diabetes Mellitus (T2DM) accounts for about $90 \%$ of all cases of Diabetes Mellitus. Dyslipidaemia has been demonstrated to form a synergy with T2DM as risk factors for cardiovascular events. This study aimed to determine the plasma levels of Lipids and Apolipoprotein B-100 among Type 2 Diabetic patients, assess the effects of Lipid Lowering agents, and to study the relationship, if any, between these lipid parameters and glycemic control.
\end{abstract}

Methods: One hundred and fifty participants consisting of fifty T2DM patients on a lipid-lowering agent, fifty newly diagnosed T2DM patients who are drug naïve (not on any anti-diabetic agent) and fifty apparently healthy non-diabetic controls were recruited for this study. Fasting blood samples were collected from all study participants for determination of Total Cholesterol (TC), LDL-C, Triglycerides (TG), High-Density Lipoprotein (HDL-C) and Apo B-100.

Results: The results showed significant increases in plasma TC, LDL-C, TG and Apo B-100 with a remarkable reduction in plasma HDL-C level in the Type 2 Diabetic drug naïve group compared with the treatment and control groups. There was a significant positive correlation observed between serum Apo B-100 and level of glycaemia in the T2DM drug naïve group.

Conclusion: This study further confirms the therapeutic benefits of lipid-lowering agents in reducing Apo B-100 among T2DM patients. Furthermore, maintaining good glycaemic control reduces the risk for the development of dyslipidaemia.

Keywords: T2DM, Dyslipidaemia, Cardiovascular Diseases, Apolipoprotein B-100, Nigeria.

*Corresponding author

Idowu, A.O.

ORCID - ID: http://orcid.org/0000-0003-2902-958X

kolamed2002@yahoo.com

\footnotetext{
${ }^{1}$ Department of Internal Medicine, Babcock University Teaching Hospital, Ilishan-Remo, Ogun State, Nigeria ${ }^{2}$ Benjamin S. Carson (Snr.) School of Medicine, Babcock University, Ilishan-Remo, Ogun State, Nigeria ${ }^{3}$ Department of Chemical Pathology \& Immunology, Obafemi Awolowo College of Health Sciences, Olabisi Onabanjo University, Ogun State, Nigeria.

${ }^{4}$ Department of Paediatrics, Babcock University Teaching Hospital, Ilishan-Remo, Ogun State, Nigeria

${ }^{5}$ Department of Pharmacy, Babcock University Teaching Hospital, Ilishan-Remo, Ogun State, Nigeria
}

Research Journal of Health Sciences subscribed to terms and conditions of Open Access publication. Articles are distributed under the terms of Creative Commons Licence (CC BY-NC-ND 4.0). (http://creativecommons.org/licences/by-nc-nd/4.0).

http://dx.doi.org/10.4314/rejhs.v9i1.2 


\title{
Effets des agents hypolipidémies sur le profil lipidique plasmatique et l'apolipoprotéine $B$ chez les patients diabétiques de type 2
}

\author{
Idowu, A.O. ${ }^{1,2}$, Ebesunun, M.O. ${ }^{3}$, Adekoya, A.O. ${ }^{2,4}$, Taiwo, F. ${ }^{1,2}$, Adesegun, O.A. ${ }^{1}$, \\ Idowu, A.A. ${ }^{5}$, Uka, A. ${ }^{1}$, Amusan, O.O. ${ }^{1}$, Ehioghae, O. ${ }^{1}$, Amballi, A.A.
}

\section{Résumé}

Contexte général de l'étude : Le diabète sucré de type 2 (T2DS) représente environ $90 \%$ de tous les cas de diabète sucré. Il a été démontré que la dyslipidémie forme une synergie avec le T2DS en tant que facteurs de risque d'événements cardiovasculaires. Cette étude visait à déterminer les taux plasmatiques de lipides et d'apolipoprotéine B-100 chez les patients diabétiques de type 2, à évaluer les effets des agents hypolipidémies et à étudier la relation, le cas échéant, entre ces paramètres lipidiques et le contrôle glycémique.

Méthode de l'étude : Cent cinquante participants comprenant cinquante patients T2DS sous hypolipidémies, cinquante patients T2DS nouvellement diagnostiqués qui sont naïfs de tout médicament (aucun agent antidiabétique) et cinquante témoins non diabétiques apparemment sains ont été recrutés pour cette étude. Des échantillons de sang à jeun ont été prélevés sur tous les participants à l'étude pour la détermination du cholestérol total (CT), du LDL-C, des triglycérides (TG), des lipoprotéines de haute densité (LHD-C) et de l'Apo B-100.

Résultat de l'étude : Les résultats ont montré des augmentations significatives du plasma CT, L-DL-C, TG et Apo B-100 avec une réduction remarquable du taux plasmatique de LHD-C dans le groupe diabétique de type 2 naïf par rapport aux groupes de traitement et de contrôle. Une corrélation positive significative a été observée entre le sérum Apo B-100 et le taux de glycémie dans le groupe naïf de Dt2.

Conclusion : Cette étude confirme en outre les avantages thérapeutiques des agents hypolipidémies dans la réduction de l'Apo B-100 chez les patients atteints de DT2. De plus, le maintien d'un bon contrôle glycémique réduit le risque de développement d'une dyslipidémie.

Mots-clés : DT2, dyslipidémie, maladies cardiovasculaires, apolipoprotéine B-100, Nigéria

*Corresponding author

Idowu, A.O.

ORCID - ID: http://orcid.org/0000-0003-2902-958X

kolamed2002@yahoo.com

\footnotetext{
${ }^{1}$ Department of Internal Medicine, Babcock University Teaching Hospital, Ilishan-Remo, Ogun State, Nigeria ${ }^{2}$ Benjamin S. Carson (Snr.) School of Medicine, Babcock University, Ilishan-Remo, Ogun State, Nigeria ${ }^{3}$ Department of Chemical Pathology \& Immunology, Obafemi Awolowo College of Health Sciences, Olabisi Onabanjo University, Ogun State, Nigeria.

${ }^{4}$ Department of Paediatrics, Babcock University Teaching Hospital, Ilishan-Remo, Ogun State, Nigeria ${ }^{5}$ Department of Pharmacy, Babcock University Teaching Hospital, Ilishan-Remo, Ogun State, Nigeria
} 


\section{INTRODUCTION}

Diabetes mellitus, a metabolic disease of global concern, is associated with high risk of cardiovascular morbidity and mortality. The persistent hyperglycemia characteristic of diabetes mellitus results in vascular modifications contributing to atherosclerosis and other vascular pathologies (1). Cardiovascular Diseases (CVD) are the leading cause of mortality among patients with Type 2 Diabetes Mellitus (T2DM) (2). Dyslipidemia is a state that arises as a result of abnormalities in the plasma lipids. It is one of the key risk factors for cardiovascular disease among patients with T2DM. There is a synergistic relationship between T2DM and dyslipidaemia as risk factors for cardiovascular events $(3,4)$.

In studies on the characterization of lipid parameters among patients with T2DM in Nigeria, extremely high prevalence rates of dyslipidaemia (up to $89.1 \%$ ) were reported $(5,6)$. The lipid pattern typically observed among people with T2 DM comprised hypertriglyceridemia, reduced High-Density Lipoprotein Cholesterol (HDL-C) and elevated levels of Low-Density Lipoprotein Cholesterol (LDL-C) (7).

Owing to its poor solubility in water, virtually all cholesterol in the blood is carried in lipoprotein particles. Atherogenic lipoproteins, including Low Density Lipoprotein (LDL), Very Low-Density Lipoprotein (VLDL) and Intermediate-Density Lipoprotein (IDL), contain apo B-100. One molecule of apo B-100 is present in each atherogenic particle of LDL, VLDL and IDL, making apo B-100 a potential surrogate measure of the total number of atherogenic particles in blood $(8,9)$. Apo B-100 can represent a more direct determinant of atherogenic properties of plasma lipids and is useful for the prediction of future cardiovascular events.

Few studies have been done evaluating plasma apoB-100 as a surrogate marker of atherogenesis amongst type 2 diabetics in Nigeria. Adaja et al reported positive correlations between apoB-100 and LDL, non-HDL cholesterol and total cholesterol, more so in poorly controlled diabetics (10). Sonuga et al also reported higher levels of atherogenic lipid biomarkers, including apoB-100, amongst young people with a family history of diabetes (11). Though, the use of biomarkers such as apoB-100 in clinical practice and research in Nigeria is gradually evolving, it is not yet considered as routine in the workup of type 2 diabetics.

This study aimed to determine the plasma levels of Lipids and apo B-100 among Type 2 Diabetic patients, assess the effects of Lipid Lowering agents, and study the relationship, if any, between these lipid parameters and glycemic control.

\section{MATERIALS AND METHODS Study Setting}

The study was carried out at the Endocrinology, Diabetes and Metabolism division of the Department of Internal Medicine, Olabisi Onabanjo University Teaching Hospital (OOUTH), Sagamu, as well as the Diabetes Clinic of Babcock University Teaching Hospital (BUTH), Ilishan-Remo, Ogun-State, Nigeria. These facilities provide care to the patients from surrounding towns as well as neighboring states of Lagos, Oyo and Ondo.

\section{Study Design and Sampling technique}

This was a cross-sectional, comparative, hospital-based study. One hundred and fifty participants were recruited into the study - Fifty of them were T2DM patients who had been on a lipid lowering agent for a minimum period of 3 months, another fifty T2DM drug naïve patients matched for age and sex, and fifty apparently healthy non-diabetics who served as the control group. The sample size was calculated using the Cochran formula. All those above 30 years of age, who gave their informed consent, were included in the study. Individuals on medications that could affect the plasma lipid profile and apo B100 including antipsychotics, anticonvulsants, immunosuppressants and thiazide diuretics, pregnant women and very ill diabetic patients were excluded from the study.

\section{Data Collection}

Demographic data and clinical history were obtained by interviewing the study participants and from information in their hospital case folders. Physical examination was performed on each participant to exclude those with physical findings in keeping with the exclusion criteria. Also, the peripheral stigmata of dyslipidemia were thoroughly looked out for in each study participants. Body weight, height, body mass index (BMI), waist circumference (WC), hip circumference (HC), waist-hip ratio $(\mathrm{W} / \mathrm{C})$ and blood pressure were measured in all study participants and recorded using standard methods. Laboratory assessment included collection of $10 \mathrm{mls}$ of venous blood which was carefully drawn from each participant using the ante-cubital vein under aseptic procedure of 
venipuncture between 8.00 - 8:30am after an overnight fast of at least 8 hours but not more than 12 hours.

The venous blood collected was divided appropriately as follows: $5 \mathrm{mls}$ into plain bottles for Fasting Lipid Profile (FLP) and Apo B-100 assays, while the remaining $5 \mathrm{mls}$ was equally distributed into Lithium heparin and fluoride oxalate bottles for the analysis of glycated hemoglobin (HbAlc) and fasting plasma glucose (FPG) respectively. These samples were kept in a cold chain box and transported to the laboratory for centrifugation and separation. The samples for FLP, apo B-100 and FPG were allowed to clot and thereafter centrifuged at 4000 revolutions per minute for 10 minutes, and separated within 30 minutes to extract serum and aliquoted into labelled Eppendorf bottles. Sera for FLP and apo $\mathrm{B}-100$ were stored at $-20^{\circ} \mathrm{C}$ till ready for analysis. FLP was measured spectrophotometrically using enzymatic reagents while apo B-100 was assayed using ELISA method.

Glycated hemoglobin (HbA1c) was analyzed using the Clover A1c analyzer which utilizes the boronate affinity chromatography. The linearity range for $\mathrm{HbA} 1 \mathrm{c}$ detection in this study ranged between $5.3 \%$ - 17\%. All biochemical analyses were carried out in the chemical pathology laboratory of Babcock University Teaching Hospital, Ilishan-Remo, Ogun State, using commercial kits, allowing the best performance of coefficient of variation $(\mathrm{CV})$ and sensitivity.

\section{Laboratory Procedures}

All laboratory procedures were carried out under strict and good laboratory practices. All blood samples drawn from study participants were transferred immediately into a dry-ice packed container and centrifuged within an hour after collection. Serum cholesterol and triglyceride levels were determined by enzymatic colorimetric methods using the method based on CHOD-PAP methodology. The principle is based on the methods described by Trinider and Teitz for total cholesterol and triglyceride respectively. HDL cholesterol was precipitated using the Dextran-sulphate-magnesium acetate precipitation method and analyzed as using method of Trinider. LDL cholesterol was calculated using the Friedwald formula: (LDL-C) $=($ Total Cholesterol $)-($ HDL - Cholesterol $)-$ (TG/5). Apo B-100 was estimated using an enzyme immunoassay method.

\section{Statistical Analysis}

The data obtained were coded and entered into a computer for analysis. Data were analyzed using the Statistical Package for Social Science (SPSS) version 23 (SPSS, Chicago, IL, WA). Except otherwise stated, continuous variables were expressed as mean \pm Standard Deviation (SD) and number counts (N), with proportions (\%) for categorical data. Descriptive analyses were presented with frequency tables and graphs as appropriate. Analysis of Variance (ANOVA) was used to compare the means of continuous variables with more than two groups. Thereafter, post-hoc tests were carried out on the result of ANOVA tables generated to identify the two groups with a statistically significant difference. Students' t-test was used to compare continuous variables when two groups were involved. Correlation between Apo B-100 levels and glycaemic control was done using Spearman Rho's correlation coefficient. Other categorical variables were also compared using Chi-square test with the level of statistical significance set at $\mathrm{p}<0.05$.

\section{Ethical Consideration}

Approval for the study was obtained from the Health Research and Ethics Committee of the Olabisi Onabanjo University Teaching Hospital, Sagamu, Ogun State (OOUTH-HREC) w i t h r e i s t r a t i n n u m e r OOUTH/HREC/221/2018AP. We obtained written informed consents from each participant. All relevant standards of Revised Declaration of Helsinki were followed.

\section{RESULTS}

Demographic and clinical parameters of the study participants

One hundred and fifty consecutive study participants were recruited for this study and were divided into three groups of fifty participants each. The mean age was $57.42 \pm$ 11.72 years (see Table 1), with the age range being 31-85 years. All participants were Nigerian and predominantly Yoruba by tribe (96\%). Over half of the study participants were women $(57.3 \%)$; most $(76.7 \%)$ were married with almost equal proportions of married participants in each of the three groups (see Table 2). The three groups were significantly different in the mean values of their height, weight, body mass index, waist circumference and hip circumference $(p<0.05)$. The T2DM drug-naïve group had the highest values of anthropometric parameters. The mean systolic and diastolic blood pressures differed significantly among the three groups with the control group having the lowest mean blood 
pressure values compared to the two diabetic groups $(\mathrm{p}<0.001)$ respectively, as shown in Table $3 a$ (post hoc tests in Table $3 b)$.

\section{Class and duration of lipid-lowering agents used by study participants.}

All T2DM patients in the lipid-lowering group were on statins, as shown in Table 4 . All the study participants in this group had been on statins for a minimum period of 3 months, 34\% had been on a statin for more than 2 - 5years, and $22 \%$ for more than 6 months -1 year. Only $2 \%$ of those in this group had taken a statin for more than 5 years.

\section{Relationship between duration of diabetes and use of lipid lowering agents}

There was a significant association between duration of diabetes and use of lipid lowering agents, with majority (28\%) of diabetics on lipid lowering agents having had diabetes for $>2-5$ years, and $66 \%$ of those not on lipid lowering agents having had diabetes for 0-6 months (see Table 4)

\section{Lipid profile and Apo B-100 of study participants}

Biochemical parameters among the three study groups are shown in Table 5a. The mean serum TC, LDL and TG were observed to be significantly higher in the T2DM drug-naive group than in the other two groups $(\mathrm{p}<0.05)$ (see Table 5a; post hoc tests in Table 5b). However, the mean serum HDL of the T2DM on lipid lowering agent group, T2DM drug naive group and nondiabetic control group were $50.31 \pm 20.60 \mathrm{mg} / \mathrm{L}$, $33.78 \pm 9.70 \mathrm{mg} / \mathrm{L}$ and $40.43 \pm 16.31 \mathrm{mg} / \mathrm{L}$ respectively. Thus, HDL values were significantly lower in the T2DM drug naive group compared to the other two groups $(\mathrm{p}<0.05)$ (see Table $5 \mathrm{a}$; post hoc tests in Table $5 \mathrm{~b}$ ). The mean apo B-100 was higher in the T2DM drug naive group compared to the other two groups, and this difference was statistically significant $(p<0.05)$. The mean FPG \& HbA1c (indices for glycaemic control) were also highest in the T2DM drug naive group $(\mathrm{p}<0.05)$ as shown in Table 5a (post hoc tests in Table 5b).

\section{Relationship between serum Apo B-100 and glycemic control in the diabetic groups.}

The correlation of the apo B-100 with the degree of glycaemic control using HbAlc between the two diabetic groups is shown in Table 6. There was a weak but positive correlation between Serum apo B-100 and level of glycaemic control in the T2DM on lipid lowering agent group. However, serum apo B100 was significantly correlated with the level of glycaemic control in T2DM drug naive group. Figures 1 and 2 further expressed the relationship between apo B-100 and the degree of glycaemic control using HbAlc. There is a linear relationship between apo B-100 and $\mathrm{HbA} 1 \mathrm{c}$ with the regression line-sloping upwards in the T2DM on lipid lowering agent group.

\section{Relationship between degree of glycaemic control and lipid profile parameters}

The correlation between the degree of glycaemic control using $\mathrm{HBA}_{1} \mathrm{C}$ and the lipid parameters is depicted in Table 7. In the T2DM on lipid lowering agent group HbAlc, was weakly but positively correlated with the TC and HDL. There was a negative correlation between HbA1c, LDL and TG. In the T2DM drug naive group, $\mathrm{HBA}_{1} \mathrm{C}$ was positively correlated with LDL and TG while it was negatively correlated with TC and HDL. None of the correlation coefficients were statistically significant.

\section{DISCUSSION}

Statins have been revealed to have potential therapeutic benefits in reducing atherogenic lipoproteins which include LDL-C, VLDL, IDL and apo B-100 (12-14). Affordability and availability are factors that possibly would have contributed to statins being widely used for the treatment of dyslipidemia among Type 2 Diabetics as found in this present study. Also, it is presumed that most clinicians are not updated on the novel lipid-lowering agents, indications for their initiation and their side effect profiles, thus contributing to the common use of statins over other agents in most centers.

Mean values of anthropometric indices ( $\mathrm{Wt}$, $\mathrm{BMI}, \mathrm{WC}, \mathrm{HC}$ and $\mathrm{W} / \mathrm{H}$ ) were most elevated in the T2DM statin-naive group compared to the other two groups studied. This finding is in accordance with previous studies which showed that $\mathrm{BMI}, \mathrm{WC}, \mathrm{W} / \mathrm{H}$ ratio are positive indicators of development of Type 2 Diabetes $(15,16)$. Mean values of these anthropometric indices were lower in the Type 2 Diabetics on lipid lowering agents. This can be credited to the quality of care rendered to Type 2 Diabetics which comprise counseling on dietary adjustments, lifestyle interventions targeted at reduction of central adiposity and optimizing care to improve quality oflife.

Mean serum LDL-C value was highest in the T2DM statin-naïve group compared to the 
treatment and control groups. This correlates with earlier studies which reported mean LDL-C values to be elevated in statin naive participants relative to diabetic participants on statin therapy (17-19). Diabetic dyslipidaemia encompasses both quantitative and qualitative lipoprotein abnormalities that together culminate in a shift toward a more atherogenic lipid profile that includes elevated LDL-C especially in patients who are not on lipid-lowering medications (19). Probable explanations for this increase in LDL-C in the lipid lowering naive group include a significant decrease in the catabolism of LDL $(20,21)$. This may ultimately precipitate lipid deposition within arterial walls increasing the risk of cardiovascular morbidity. Also, the increase in LDL-C levels in the statin-naive group can be attributed to the reduction of LDL cell-surface receptors compared to the group on statins (21). It is worthy of note that statins have been reported to increase cell surface LDL receptor expression resulting in facilitation of increased clearance of LDL-C from the bloodstream and a subsequent reduction in circulating LDL-C levels by 20 to $55 \%$, hence the reduced LDL-C in the Type 2 Diabetic on lipid lowering agent group in this study (22). Previous studies have also suggested increased glycation of LDL secondary to chronic hyperglycaemia as a cause of elevated LDL-C $(23,24)$. This present study also found elevated mean glycated hemoglobin in the drug naïve group which further supports a possible increase in non-enzymatic glycation of proteins including LDL-C.

As had been reported elsewhere and confirmed in this study, statins have the capacity to increase the concentration of HDL-C (25). In this study, the mean serum HDL-C level was higher in the T2DM on lipid-lowering agent group compared to the drug naïve group. In this study, the statin-mediated elevation of HDL-C level in the T2DM on lipid-lowering agents is in consonance with previous studies with similar findings. With statins, there are elevations in HDL-C range between $3 \%$ and $15 \%$ (26).

Mean Triglyceride levels were significantly higher in the T2DM not on lipid lowering agent. This may be somewhat attributed to an increased number of VLDL. The production rate of VLDL in patients with Diabetic dyslipidemia yet to initiate lipid lowering agent has a positive correlation with the insulin resistance in these patients (27). Statins decrease TG levels by endocytosing TG-rich Apo B-100 particles (28), hence, the reduction in mean TG concentration among the T2DM on statin in this study.

Mean apo B-100 level which is considered to be an approximation of the total number of atherogenic particles is highest in the T2DM not on statins compared to the two other groups. Apo B-100 is the goal of therapy of the ADA/ACC consensus statement on lipoprotein management in patients with Cardio-metabolic risk. Statins lower LDL-C and VLDL both of which are atherogenic lipids containing apo B100. A management consideration for the highrisk patient is to assay apo-B during statin therapy to make sure that the total number of atherogenic particles is decreased (28). Biochemical indicators for glycaemia including $\mathrm{HbA}_{1 \mathrm{c}}$ and FPG are also significantly elevated in the drugnaïve group compared to the treatment group. This indicates the therapeutic benefit of glucose lowering agent and also exemplify compliance with medications, routine clinic visits and possibly regular lifestyle interventions as recommended by their managing Physicians/Endocrinologists. Apo B-100 had a linear relationship with $\mathrm{HbA}_{1 \mathrm{c}}$ as a measure of glycaemic control in both diabetic groups. There was a significant positive correlation observed in the T2DM drug naive group. The findings from this study consistently suggested that elevated apo B-100 levels was associated with poor glycaemic control which is in accordance with previous studies (29-31).

Hwang et al indicated that Apo B-100 is an effective predictor of $\mathrm{T}_{2} \mathrm{DM}$ (32). In patients with diabetic dyslipidemia who are drug naive, apo B-100 containing lipoprotein particles undergo compositional changes, including the increased formation of LDL and TG particles as also seen in this present study (33). The poorer the glycaemic control is, the higher the level of apo $\mathrm{B}-100$ is, especially in the drug naive group.

\section{Limitations of the Study}

The choice of lipid lowering agent used in this study was limited to statins. This study was not able to compare the effect of statins with the other lipid lowering agents and did not categorize individual type of statin used. Also, the study was performed using a cross-sectional design and did not control for potential biases from diet, physical activity, smoking and alcohol history, and duration of statin use. A longitudinal study would have served this purpose better, however limitations in funding and other logistics prevented this from being implemented in the current study. 


\section{CONCLUSION}

This study further confirms the therapeutic benefits of statins in reducing atherogenic lipids and Apo B-100 among T2DM patients as previously reported. Also, the study corroborates earlier studies regarding the positive correlation between poor glycemic control and the risk of developing dyslipidemia.

Recommendations: Physicians should be trained at all levels of care about the other lipid lowering agents, indications for use and side effect profile so as to provide holistic care for T2DM patients. With the already available direct measures to establish the severity of dyslipidemia by assaying the conventional lipoproteins, apo B100 can be added as a surrogate/potential biomarker as this correlate better with progression of the disease. Finally, further studies should pay more attention to Apo $\mathrm{B} / \mathrm{Apo} \mathrm{A} 1$ ratio which reflects the balance of atherogenic and athero-protective particles and provides a unique assessment of cardiovascular risk.

Competing Interests: Authors have declared no conflict of interest.

Funding: This research work did not receive any grant from any funding agency in the public, commercial or not-for-profit sector.

\section{REFERENCES}

1. Paneni F, Beckman JA, Creager MA, Cosentino F. Diabetes and vascular disease: Pathophysiology, clinical consequences, and medical therapy: Part 1 [Internet]. Vol. 34, European Heart Journal. Oxford University Press; 2013. p. 2436-46.

2. Wright AK, Kontopantelis E, Emsley R, Buchan I, Sattar N, Rutter MK, et al. Life expectancy and cause-specific mortality in type 2 diabetes: A population-based cohort study quantifying relationships in ethnic subgroups. Diabetes Care 2017;40(3):338-45.

3. Morrish NJ, Wang SL, Stevens LK, Fuller JH, Keen H. Mortality and causes of death in the WHO multinational study of vascular disease in diabetes. Diabetologia 2001;44:S14-21.

4. Chehade JM, Gladysz M, Mooradian AD. Dyslipidemia in type 2 diabetes: Prevalence, pathophysiology, and management. Drugs 2013;73(4):327-39.

5. Ogbera AO, Fasanmade OA, Chinenye S, Akinlade A. Characterization of lipid parameters in diabetes mellitus - A Nigerian report. Int Arch Med 2009;2(1):19.

6. Okafor C, Fasanmade O, Oke D. Pattern of dyslipidaemia among Nigerians with type 2 diabetes mellitus. Niger J Clin Pract 2008;11(1):25-31.
7. Wing RR, Lang W, Wadden TA, Safford M, Knowler WC, Bertoni AG, et al. Benefits of modest weight loss in improving cardiovascular risk factors in overweight and obese individuals with type 2 diabetes. Diabetes Care 2011;34(7):1481-6.

8. Fazio S, Shapiro MD. Apolipoprotein Bcontaining lipoproteins and atherosclerotic cardiovascular disease [Internet]. Vol. 6, F1000Research. Faculty of 1000 Ltd; 2017.

9. Morita SY. Metabolism and modification of apolipoprotein B-containing lipoproteins involved in dyslipidemia and atherosclerosis. Vol. 39, Biological and Pharmaceutical Bulletin. Pharmaceutical Society of Japan; 2016. p. 1-24.

10. Adaja T, Ojo M, Ayina C. Chapter 6 - Relationship of Apolipoprotein B-100 and Lipid Profile Parameters among Diabetic Patients in a Tertiary Hospital in Nigeria. In: Current Trends in Disease and Health Vol 2 2019. p. 75-84.

11. Sonuga OO, Abbiyesuku FM, Adedapo KS, Sonuga AA. Insulin Resistance Index and Proatherogenic Lipid Indices in the Offspring of People with Diabetes. Int $\mathrm{J}$ Diabetes Metab 2019;25(1-2):11-8.

12. Meikle PJ, Wong G, Tan R, Giral P, Robillard P, Orsoni A, et al. Statin action favors normalization of the plasma lipidome in the atherogenic mixed dyslipidemia of MetS: Potential relevance to statin-associated dysglycemia. J Lipid Res 2015;56(12):2381-92.

13. Baigent C, Blackwell L, Emberson J, Holland LE, Reith C, Bhala N, et al. Efficacy and safety of more intensive lowering of LDL cholesterol: A metaanalysis of data from 170000 participants in 26 $\mathrm{r}$ a $\mathrm{n} \mathrm{do} \mathrm{mis} \mathrm{e} \mathrm{d} \mathrm{tr}$ i a $1 \mathrm{~s}$. L a $\mathrm{n} \mathrm{ce} \mathrm{t}$ 2010;376(9753):1670-81.

14. Lamon-Fava S, Diffenderfer MR, Barrett PHR, Buchsbaum A, Matthan NR, Lichtenstein AH, et al. Effects of different doses of atorvastatin on human apolipoprotein B-100, B-48, and A-I metabolism. J Lipid Res 2007;48(8):1746-53.

15. Hadaegh F, Shafiee G, Azizi F. Anthropometric predictors of incident type 2 diabetes mellitus in Iranian women. Ann Saudi Med 2009;29(3):194.

16. Yang J, Wang F, Wang J, Han X, Hu H, Yu C, et al. Using different anthropometric indices to assess prediction ability of type 2 diabetes in elderly population: A 5 year prospective study. BMC Geriatr 2018;18(1):218.

17. Grappin M, Piroth L, Verges B, Sgro C, Mack G, Buisson $\mathrm{M}$, et al. Increased prevalence of subclinical hypothyroidism in HIV patients treated with highly active antiretroviral therapy. AIDS 2000;14(8):1070-2.

18. Taskinen MR. Diabetic dyslipidaemia: From basic research to clinical practice [Internet]. Vol. 46, Diabetologia. Diabetologia; 2003.p. 733-49.

19. Wang J, Stančáková A, Soininen P, Kangas AJ, Paananen J, Kuusisto J, et al. Lipoprotein subclass profiles in individuals with varying degrees of glucose tolerance: A population-based study of 
9399 Finnish men. J Intern Med 2012;272(6):562-72.

20. Stolinski M, Alam S, Jackson NC, ShojaeeMoradie F, Pentecost C, Jefferson W, et al. Effect of 6-month supervised exercise on low-density lipoprotein apolipoprotein B kinetics in patients with type 2 diabetes mellitus. Metabolism 2008;57(11):1608-14.

21. Duvillard L, Florentin E, Lizard G, Petit JM, Galland F, Monier S, et al. Cell surface expression of LDL receptor is decreased in type 2 diabetic patients and is normalized by insulin therapy. Diabetes Care 2003;26(5):1540-4.

22. Ko SH, Cha BY. Diabetic peripheral neuropathy in type 2 diabetes mellitus in Korea [Internet]. Vol. 36, Diabetes and Metabolism Journal. Korean Diabetes Association; 2012.p. 6-12.

23. Rabbani N, Chittari MV, Bodmer CW, Zehnder D, Ceriello A, Thornalley PJ. Increased glycation and oxidative damage to apolipoprotein B100 of LDL cholesterol in patients with type 2 diabetes and effect of metformin. Diabetes 2010;59(4):1038-45.

24. Makita T, Tanaka A, Nakano T, Nakajima K, Numano F. Importance of glycation in the acceleration of low density lipoprotein (LDL) uptake into macrophages in patients with diabetes mellitus. Int Angiol 1999;18(2):149-53.

25. McTaggart F, Jones P. Effects of statins on highdensity lipoproteins: A potential contribution to cardiovascular benefit [Internet]. Vol. 22, Cardiovascular Drugs and Therapy. Springer; 2008.p. 321-38.

26. Barter P. Options for therapeutic intervention: How effective are the different agents? Eur Hear Journal, Suppl 2006;8(F):F47-53.
27. Adiels M, Borén J, Caslake MJ, Stewart P, Soro A, Westerbacka J, et al. Overproduction of VLDL1 driven by hyperglycemia is a dominant feature of diabetic dyslipidemia. Arterioscler Thromb Vasc Biol 2005;25(8):1697-703.

28. Chirieac D V., Collins HL, Cianci J, Sparks JD, Sparks CE. Altered triglyceride-rich lipoprotein production in Zucker diabetic fatty rats. Am J Physiol - Endocrinol Metab 2004;287(1 501):42-9.

29. Sierra-Johnson J, Somers VK, Kuniyoshi FHS, Garza CA, Isley WL, Gami AS, et al. Comparison of Apolipoprotein-B/Apolipoprotein-AI in Subjects With Versus Without the Metabolic Syndrome. Am J Cardiol 2006;98(10):1369-73.

30. Wallenfeldt K, Bokemark L, Wikstrand J, Hulthe J, Fagerberg B. Apolipoprotein B/apolipoprotein A-I in relation to the metabolic syndrome and change in carotid artery intima-media thickness during 3 years in middle-aged men. Stroke 2004;35(10):2248-52.

31. Mallick AK, Maradi R, Joshi VR, Bhat PG. A Study on Apo B100 / Apo a-I Ratio in Uncontrolled Type 2 Diabetes Mellitus. Int J Appl Biol Pharm Technol 2011;2(1):379-84.

32. Hwang YC, Ahn HY, Kim WJ, Park CY, Park SW. Increased apoB/A-I ratio independently associated with Type 2 diabetes mellitus: crosssectional study in a Korean population. Diabet Med 2012;29(9):1165-70.

33. Mora S, Otvos JD, Rosenson RS, Pradhan A, Buring JE, Ridker PM. Lipoprotein particle size and concentration by nuclear magnetic resonance and incident type 2 diabetes in women. Diabetes 2010;59(5):1153-60

How to cite this article:

Idowu, A.O., Ebesunun, M.O., Adekoya, A.O., Taiwo, F., Adesegun, O.A., Idowu, A.A., Uka, A., Amusan, O.O., Ehioghae, O., Amballi, A.A. Effects of lipid-lowering agents on plasma lipid profile and apolipoprotein B in patients with type 2 diabetes mellitus. Research Journal of Health Science, 2021, 9(1): 8-22 
Table 1: Mean Age of Study Participants

\begin{tabular}{llllll}
\hline AGE & DM-L & DM-L $^{0}$ & CN & Test & p-value \\
& Mean \pm SD & Mean \pm SD & statistics & \\
& & & Mean \pm SD & value &
\end{tabular}

(ANOVA)

\begin{tabular}{llllll}
\hline AGE & $57.86 \pm 11.48$ & $56.62 \pm 12.48$ & $57.78 \pm 11.37$ & 0.173 & 0.841
\end{tabular}

Mean age of all participants $=\mathbf{5 7 . 4 2} \pm 11.72$ years

DM-L - Diabetics on lipid lowering agent, DM- $\mathrm{L}^{0}-$ Diabetics not on lipid lowering agent, $\mathrm{CN}$ - Control, $\mathrm{N}-$ Total Number, ${ }^{*} \mathrm{p}$ value $<0.05$ is statistically significant.

Table 2: Socio-Demographic characteristics of the study population

\begin{tabular}{|c|c|c|c|c|c|c|}
\hline CHARACTERISTICS & $\begin{array}{l}\text { DM-L } \\
(\%) \\
\text { N=50 }\end{array}$ & $\begin{array}{l}\text { DM-L0 } \\
(\%) \\
\mathbf{N}=\mathbf{5 0}\end{array}$ & $\begin{array}{l}\text { CN } \\
(\%) \\
N=50\end{array}$ & $\begin{array}{l}\text { Total } \\
(\%)\end{array}$ & $\begin{array}{l}\text { Test } \\
\text { Statistics } \\
\text { Value }\left(\mathbf{X}^{2}\right)\end{array}$ & p-Value \\
\hline \multicolumn{7}{|l|}{ TRIBE } \\
\hline Yoruba & $47(94.0)$ & $47(94.0)$ & $50(100.0)$ & $144(96.0)$ & 6.577 & 0.160 \\
\hline Hausa & $0(0.0)$ & $1(2.0)$ & $0(0.0)$ & $1(0.7)$ & & \\
\hline Igbo & $3(6.0)$ & $2(4.0)$ & $0(0.0)$ & $5(3.3)$ & & \\
\hline \multicolumn{7}{|l|}{ GENDER } \\
\hline Male & $16(32.0)$ & $27(54.0)$ & $21(42.0)$ & $64(42.7)$ & 4.960 & 0.084 \\
\hline Female & $34(68.0)$ & $23(46.0)$ & $29(58.0)$ & $86(57.3)$ & & \\
\hline \multicolumn{7}{|l|}{ OCCUPATION } \\
\hline Civil Service & $11(22.0)$ & $13(26.0)$ & $13(26.0)$ & $37(24.7)$ & 22.239 & $0.035^{*}$ \\
\hline Self-employed & $21(42.0)$ & $24(48.0)$ & $27(54.0)$ & $72(48.0)$ & & \\
\hline Unemployed & $0(0.0)$ & $1(2.0)$ & $3(6.0)$ & $4(2.7)$ & & \\
\hline Apprentice & $0(0.0)$ & $0(0.0)$ & $2(4.0)$ & $2(1.3)$ & & \\
\hline Retired & $16(32.0)$ & $11(22.0)$ & $3(6.0)$ & $30(20.0)$ & & \\
\hline Student & $1(2.0)$ & $1(2.0)$ & $2(4.0)$ & $4(2.7)$ & & \\
\hline Others & $1(2.0)$ & $0(0.0)$ & $0(0.0)$ & $1(0.7)$ & & \\
\hline \multicolumn{7}{|l|}{ MARITAL STATUS } \\
\hline Single & $1(2.0)$ & $2(4.0)$ & $7(14.0)$ & $10(6.7)$ & 20.618 & $0.002 *$ \\
\hline Married & $39(78.0)$ & $38(76.0)$ & $38(76.0)$ & $115(76.7)$ & & \\
\hline Separated & $0(0.0)$ & $6(12.0)$ & $3(6.0)$ & $9(6.0)$ & & \\
\hline Widow/Widower & $10(20.0)$ & $4(8.0)$ & $2(4.0)$ & $16(10.7)$ & & \\
\hline \multicolumn{7}{|c|}{ EDUCATIONAL STATUS } \\
\hline None & $7(14.0)$ & $2(4.0)$ & $0(0.0)$ & $9(6.0)$ & 29.073 & $0.001 *$ \\
\hline Primary & $9(18.0)$ & $3(6.0)$ & $1(2.0)$ & $13(8.7)$ & & \\
\hline Secondary & $9(18.0)$ & $7(14.0)$ & $17(34.0)$ & $33(22.0)$ & & \\
\hline Tertiary & $22(44.0)$ & $37(74.0)$ & $30(60.0)$ & $89(59.3)$ & & \\
\hline Technical & $2(4.0)$ & $1(2.0)$ & $1(2.0)$ & $4(2.7)$ & & \\
\hline Vocational Training & $1(2.0)$ & $0(0.0)$ & $1(2.0)$ & $2(1.3)$ & & \\
\hline \multicolumn{7}{|l|}{ RELIGION } \\
\hline Christianity & $30(60.0)$ & $43(86.0)$ & $46(92.0)$ & $119(79.3)$ & 17.647 & $0.001 *$ \\
\hline Islam & $20(40.0)$ & $7(14.0)$ & $4(8.0)$ & $31(20.7)$ & & \\
\hline
\end{tabular}


Table 3a: Comparative Values of Anthropometric Indices and Blood Pressure in Study Participants

\begin{tabular}{|c|c|c|c|c|c|}
\hline VARIABLES & $\begin{array}{l}\text { DM-L } \\
\text { Mean } \pm \text { SD }\end{array}$ & $\begin{array}{l}\text { DM-L0 } \\
\text { Mean } \pm \text { SD }\end{array}$ & CN Mean \pm SD & $\begin{array}{l}\text { Test statistics } \\
\text { value } \\
(\text { ANOVA) }\end{array}$ & p-value \\
\hline $\mathrm{Ht}(\mathrm{m})$ & $1.64 \pm 0.09$ & $1.66 \pm 0.09$ & $1.70 \pm 0.09$ & 5.889 & $0.003^{*}$ \\
\hline Wt (kg) & $75.18 \pm 16.96$ & $84.42 \pm 12.95$ & $72.51 \pm 10.77$ & 10.256 & $0.001^{*}$ \\
\hline BMI $\left(\mathrm{kg} / \mathrm{m}^{2}\right)$ & $27.53 \pm 5.20$ & $30.46 \pm 4.00$ & $26.03 \pm 4.22$ & 12.483 & $0.001^{*}$ \\
\hline $\mathrm{WC}(\mathrm{cm})$ & $90.54 \pm 14.04$ & $97.07 \pm 8.56$ & $79.05 \pm 8.10$ & 37.158 & $0.001^{*}$ \\
\hline $\mathrm{HC}(\mathrm{cm})$ & $99.32 \pm 10.60$ & $104.37 \pm 8.25$ & $97.00 \pm 8.20$ & 8.597 & $0.001^{*}$ \\
\hline $\mathrm{W} / \mathrm{H}$ & $0.90 \pm 0.15$ & $0.91 \pm 0.13$ & $0.76 \pm 0.22$ & 12.213 & $0.001^{*}$ \\
\hline SBP $(\mathrm{mmHg})$ & $132.42 \pm 13.73$ & $138.16 \pm 14.48$ & $122.42 \pm 11.08$ & 18.276 & $0.001^{*}$ \\
\hline DBP $(m m H g)$ & $76.96 \pm 15.27$ & $86.44 \pm 8.51$ & $76.92 \pm 8.14$ & 12.141 & $0.001^{*}$ \\
\hline
\end{tabular}

DM-L - Diabetics on lipid lowering agent, DM-L ${ }^{0}-$ Diabetics not on lipid lowering agent, CN - Control, Ht: Height, Wt: Weight, BMI: Body Mass Index, WC: Waist Circumference, HC: Hip Circumference, W/H: Waist/Hip ratio, SBP: Systolic Blood Pressure, DBP: Diastolic Blood Pressure, ${ }^{*} \mathrm{P}$ value $<0.05$ is statistically significant. 
Table 3b - Tukey HSD Post Hoc Test for Anthropometric Indices and Blood Pressure in Study Participants

\begin{tabular}{|c|c|c|c|c|c|c|}
\hline \multirow{2}{*}{ Variables } & & & \multirow[b]{2}{*}{$\begin{array}{l}\text { Mean } \\
\text { Difference }\end{array}$} & \multirow[b]{2}{*}{ p value } & \multicolumn{2}{|c|}{ 95\% Confidence Interval } \\
\hline & & & & & $\begin{array}{l}\text { Lower } \\
\text { Bound }\end{array}$ & $\begin{array}{l}\text { Upper } \\
\text { Bound } \\
\end{array}$ \\
\hline \multirow[t]{6}{*}{ Height (m) } & DM-L & DM-L0 & -.02240 & 0.410 & -.0639 & .0191 \\
\hline & & Control & $-.05958^{*}$ & 0.003 & -.1011 & -.0181 \\
\hline & DM-L0 & DM-L & .02240 & 0.410 & -.0191 & .0639 \\
\hline & & Control & -.03718 & 0.089 & -.0787 & .0043 \\
\hline & Control & DM-L & $.05958^{*}$ & 0.003 & .0181 & .1011 \\
\hline & & DM-L0 & .03718 & 0.089 & -.0043 & .0787 \\
\hline \multirow[t]{6}{*}{ Weight (Kg) } & DM-L & DM-L0 & $-9.2400^{*}$ & 0.003 & -15.775 & -2.705 \\
\hline & & Control & 2.6700 & 0.599 & -3.865 & 9.205 \\
\hline & DM-L0 & DM-L & $9.2400^{*}$ & 0.003 & 2.705 & 15.775 \\
\hline & & Control & $11.9100^{*}$ & 0.000 & 5.375 & 18.445 \\
\hline & Control & DM-L & -2.6700 & 0.599 & -9.205 & 3.865 \\
\hline & & DM-L0 & $-11.9100^{*}$ & 0.000 & -18.445 & -5.375 \\
\hline \multirow{6}{*}{$\begin{array}{l}\text { Body Mass Index } \\
(\mathrm{Kg} / \mathrm{m} 2)\end{array}$} & DM-L & DM-L0 & $-2.93040^{*}$ & 0.004 & -5.0642 & -.7966 \\
\hline & & Control & 1.49560 & 0.224 & -.6382 & 3.6294 \\
\hline & DM-L0 & DM-L & $2.93040^{*}$ & 0.004 & .7966 & 5.0642 \\
\hline & & Control & $4.42600^{*}$ & 0.000 & 2.2922 & 6.5598 \\
\hline & Control & DM-L & -1.49560 & 0.224 & -3.6294 & .6382 \\
\hline & & DM-L0 & $-4.42600^{*}$ & 0.000 & -6.5598 & -2.2922 \\
\hline \multirow{6}{*}{$\begin{array}{l}\text { Waist Circumference } \\
(\mathrm{cm})\end{array}$} & DM-L & DM-L0 & $-6.5300^{*}$ & 0.007 & -11.541 & -1.519 \\
\hline & & Control & $11.4900^{*}$ & 0.000 & 6.479 & 16.501 \\
\hline & DM-L0 & DM-L & $6.5300^{*}$ & 0.007 & 1.519 & 11.541 \\
\hline & & Control & $18.0200^{*}$ & 0.000 & 13.009 & 23.031 \\
\hline & Control & DM-L & $-11.4900^{*}$ & 0.000 & -16.501 & -6.479 \\
\hline & & DM-L0 & $-18.0200^{*}$ & 0.000 & -23.031 & -13.009 \\
\hline \multirow[t]{6}{*}{ Hip Circumference } & DM-L & DM-L0 & $-5.0500^{*}$ & 0.017 & -9.353 & -.747 \\
\hline & & Control & 2.3200 & 0.411 & -1.983 & 6.623 \\
\hline & DM-L0 & DM-L & $5.0500^{*}$ & 0.017 & .747 & 9.353 \\
\hline & & Control & $7.3700^{*}$ & 0.000 & 3.067 & 11.673 \\
\hline & Control & DM-L & -2.3200 & 0.411 & -6.623 & 1.983 \\
\hline & & DM-L0 & $-7.3700^{*}$ & 0.000 & -11.673 & -3.067 \\
\hline \multirow[t]{6}{*}{ Waist/Hip Ratio } & DM-L & DM-L0 & -.01684 & 0.871 & -.0964 & .0627 \\
\hline & & Control & $.13470^{*}$ & 0.000 & .0551 & .2143 \\
\hline & DM-L0 & DM-L & .01684 & 0.871 & -.0627 & .0964 \\
\hline & & Control & $.15154^{*}$ & 0.000 & .0720 & .2311 \\
\hline & Control & DM-L & $-.13470^{*}$ & 0.000 & -.2143 & -.0551 \\
\hline & & DM-L0 & $-.15154^{*}$ & 0.000 & -.2311 & -.0720 \\
\hline \multirow{6}{*}{$\begin{array}{l}\text { Systolic Blood } \\
\text { Pressure (mmHg) }\end{array}$} & DM-L & DM-L0 & -5.740 & 0.078 & -11.98 & .50 \\
\hline & & Control & $10.000^{*}$ & 0.001 & 3.76 & 16.24 \\
\hline & DM-L0 & DM-L & 5.740 & 0.078 & -.50 & 11.98 \\
\hline & & Control & $15.740^{*}$ & 0.000 & 9.50 & 21.98 \\
\hline & Control & DM-L & $-10.000^{*}$ & 0.001 & -16.24 & -3.76 \\
\hline & & DM-L0 & $-15.740^{*}$ & 0.000 & -21.98 & -9.50 \\
\hline \multirow{6}{*}{$\begin{array}{l}\text { Diastolic Blood } \\
\text { Pressure (mmHg) }\end{array}$} & DM-L & DM-L0 & $-9.482^{*}$ & 0.000 & -14.75 & -4.21 \\
\hline & & Control & .038 & 1.000 & -5.23 & 5.31 \\
\hline & DM-L0 & DM-L & $9.482^{*}$ & 0.000 & 4.21 & 14.75 \\
\hline & & Control & $9.520^{*}$ & 0.000 & 4.25 & 14.79 \\
\hline & Control & DM-L & -.038 & 1.000 & -5.31 & 5.23 \\
\hline & & DM-L0 & $-9.520^{*}$ & 0.000 & -14.79 & -4.25 \\
\hline
\end{tabular}

The mean difference is significant at the 0.05 level 
Table 4 Comparison between duration of diabetes and use of lipid lowering agents

\begin{tabular}{llllll}
\hline VARIABLES & $\begin{array}{l}\text { DM-L } \\
\mathbf{( \% )} \\
\mathbf{N}=\mathbf{5 0}\end{array}$ & $\begin{array}{l}\text { DM-L } \\
\mathbf{( \% )} \\
\mathbf{N}=\mathbf{5 0}\end{array}$ & $\begin{array}{l}\text { Total } \\
\mathbf{( \% )}\end{array}$ & $\begin{array}{l}\text { Test } \\
\text { Statistics } \\
\text { Value }\left(\mathbf{X}^{2}\right)\end{array}$ & p-Value \\
\hline $\begin{array}{l}\text { Duration of diagnosis } \\
\text { 0 - 6months }\end{array}$ & $6(12.0)$ & $33(66.0)$ & $39(39.0)$ & 85.126 & $0.001^{*}$ \\
6months - 1year & $4(8.0)$ & $16(32.0)$ & $20(20.0)$ & & \\
$>$ 1year - 2years & $0(0.0)$ & $1(2.0)$ & $1(1.0)$ & \\
$>$ 2 - 5years & $14(28.0)$ & $0(0.0)$ & $14(14.0)$ & \\
>5 - 10years & $10(20.0)$ & $0(0.0)$ & $10(10.0)$ & \\
$>$ 10years & $16(32.0)$ & $0(0.0)$ & $16(16.0)$ & \\
\hline
\end{tabular}

DM-L - Diabetics on lipid lowering agent, DM-L ${ }^{0}-$ Diabetics not on lipid lowering agent, OAD - Oral Anti-diabetic Drugs,

Table 5a: Biochemical parameters of study participants

\begin{tabular}{llllll}
\hline PARAMETERS & $\begin{array}{l}\text { DM-L } \\
\text { Mean } \pm \text { SD }\end{array}$ & $\begin{array}{l}\text { DM-L } \\
\text { Mean } \pm \text { SD }\end{array}$ & $\begin{array}{l}\text { CN } \\
\text { Mean } \pm \text { SD }\end{array}$ & $\begin{array}{l}\text { Test } \\
\text { statistics } \\
\text { value } \\
\text { (ANOVA) }\end{array}$ & p-value \\
\hline TC $(\mathrm{mg} / \mathrm{dl})$ & $172.15 \pm 47.95$ & $215.28 \pm 38.70$ & $181.49 \pm 33.45$ & 15.709 & $0.001^{*}$ \\
LDL (mg/dl) & $99.02 \pm 48.24$ & $144.66 \pm 39.27$ & $125.01 \pm 36.86$ & 15.035 & $0.001^{*}$ \\
HDL (mg/dl) & $50.31 \pm 20.60$ & $33.78 \pm 9.70$ & $40.43 \pm 16.31$ & 13.230 & $0.001^{*}$ \\
TG (mg/dl) & $114.12 \pm 54.99$ & $169.58 \pm 69.13$ & $80.26 \pm 31.03$ & 34.797 & $0.001^{*}$ \\
Apo B (mg/ml) & $0.0237 \pm 0.014$ & $0.0244 \pm 0.0265$ & $0.0163 \pm 0.0008$ & 3.206 & $0.043^{*}$ \\
FPG (mg/dl) & $139.14 \pm 51.43$ & $182.10 \pm 57.91$ & $84.02 \pm 8.72$ & 59.694 & $0.001^{*}$ \\
HBA1c (\%) & $8.26 \pm 1.94$ & $9.08 \pm 1.81$ & $4.54 \pm 0.31$ & 18.382 & $0.001^{*}$ \\
\hline
\end{tabular}

DM-L - Diabetics on lipid lowering agent, DM-L ${ }^{0}-$ Diabetics not on lipid lowering agent, CN - Control, TC Total Cholesterol, LDL - Low Density Lipoprotein, HDL - High Density Lipoprotein, TG - Triglycerides, Apo B - Apo lipoprotein B, FPG - Fasting Plasma Glucose, HBA1c - Glycosylated Hemoglobin, *P value $<0.05$ is statistically significant 
Table 5b: Tukey HSD Post Hoc Test for Biochemical parameters of study participants

\begin{tabular}{|c|c|c|c|c|c|c|}
\hline \multirow{3}{*}{ Variables } & & & \multirow{3}{*}{$\begin{array}{l}\text { Mean } \\
\text { Difference }\end{array}$} & \multirow[b]{3}{*}{ p value } & \multicolumn{2}{|c|}{ 95\% Confidence Interval } \\
\hline & & & & & & Upper \\
\hline & & & & & Lower Bound & Bound \\
\hline \multirow{6}{*}{$\begin{array}{l}\text { Total Cholesterol } \\
(\mathrm{mg} / \mathrm{dl})\end{array}$} & DM-L & DM-L ${ }^{0}$ & -30.944 & 0.001 & -50.437 & -11.452 \\
\hline & & Control & 6.322 & 0.723 & -13.170 & 25.814 \\
\hline & DM-L ${ }^{0}$ & DM-L & 30.944 & 0.001 & 11.452 & 50.437 \\
\hline & & Control & 37.266 & 0.000 & 17.774 & 56.759 \\
\hline & Control & DM-L & -6.322 & 0.723 & -25.814 & 13.170 \\
\hline & & $\mathrm{DM}-\mathrm{L}^{0}$ & -37.266 & 0.000 & -56.759 & -17.774 \\
\hline \multirow{6}{*}{$\begin{array}{l}\text { LDL Cholesterol } \\
(\mathrm{mg} / \mathrm{dl})\end{array}$} & DM-L & $\mathrm{DM}-\mathrm{L}^{0}$ & -45.638 & 0.000 & -65.406 & -25.870 \\
\hline & & Control & -25.986 & 0.006 & -45.755 & -6.218 \\
\hline & DM- $\mathrm{L}^{0}$ & DM-L & 45.638 & 0.000 & 25.870 & 65.406 \\
\hline & & Control & 19.651 & 0.052 & -0.117 & 39.420 \\
\hline & Control & DM-L & 25.986 & 0.006 & 6.218 & 45.755 \\
\hline & & $\mathrm{DM}-\mathrm{L}^{0}$ & -19.652 & 0.052 & -39.420 & 0.117 \\
\hline \multirow{6}{*}{$\begin{array}{l}\text { HDL Cholesterol } \\
(\mathrm{mg} / \mathrm{dl})\end{array}$} & DM-L & $\mathrm{DM}-\mathrm{L}^{0}$ & 16.534 & 0.000 & 8.875 & 24.193 \\
\hline & & Control & 9.884 & 0.007 & 2.225 & 17.543 \\
\hline & DM-L ${ }^{0}$ & DM-L & -16.534 & 0.000 & -24.193 & -8.875 \\
\hline & & Control & -6.6500 & 0.103 & -14.309 & 1.009 \\
\hline & Control & DM-L & -9.884 & 0.007 & -17.543 & -2.225 \\
\hline & & $\mathrm{DM}-\mathrm{L}^{0}$ & 6.650 & 0.103 & -1.009 & 14.309 \\
\hline \multirow[t]{6}{*}{ Triglycerides (mg/dl) } & DM-L & $\mathrm{DM}-\mathrm{L}^{0}$ & -55.464 & 0.000 & -81.060 & -29.868 \\
\hline & & Control & 33.854 & 0.006 & 8.258 & 59.450 \\
\hline & DM-L ${ }^{0}$ & DM-L & 55.464 & 0.000 & 29.868 & 81.060 \\
\hline & & Control & 89.318 & 0.000 & 63.722 & 114.914 \\
\hline & Control & DM-L & -33.854 & 0.006 & -59.450 & -8.258 \\
\hline & & $\mathrm{DM}-\mathrm{L}^{0}$ & -89.318 & 0.000 & -114.914 & -63.722 \\
\hline \multirow{6}{*}{$\begin{array}{l}\text { Apolipoprotein B } \\
(\mathrm{mg} / \mathrm{ml})\end{array}$} & DM-L & $\mathrm{DM}-\mathrm{L}^{0}$ & -0.0006 & 0.979 & -.008936 & 0.007556 \\
\hline & & Control & 0.0074860 & 0.084 & -.000760 & 0.015732 \\
\hline & DM-L ${ }^{0}$ & DM-L & 0.0006900 & 0.979 & -.007556 & 0.008936 \\
\hline & & Control & 0.0081760 & 0.053 & -.000070 & 0.016422 \\
\hline & Control & DM-L & -0.0074860 & 0.084 & -.015732 & 0.000760 \\
\hline & & $\mathrm{DM}-\mathrm{L}^{0}$ & -0.0081760 & 0.053 & -.016422 & 0.000070 \\
\hline \multirow{6}{*}{$\begin{array}{l}\text { Fasting Plasma } \\
\text { Glucose }(\mathrm{mg} / \mathrm{dl})\end{array}$} & DM-L & $\mathrm{DM}-\mathrm{L}^{0}$ & -42.964 & 0.000 & -64.27 & -21.66 \\
\hline & & Control & 55.120 & 0.000 & 33.81 & 76.43 \\
\hline & DM-L ${ }^{0}$ & DM-L & 42.964 & 0.000 & 21.66 & 64.27 \\
\hline & & Control & 98.084 & 0.000 & 76.78 & 119.39 \\
\hline & Control & DM-L & -55.120 & 0.000 & -76.43 & -33.81 \\
\hline & & DM-L ${ }^{0}$ & -98.084 & 0.000 & -119.39 & -76.78 \\
\hline \multirow[t]{6}{*}{ HBA1C (\%) } & DM-L & DM-L ${ }^{0}$ & -0.822 & 0.023 & -1.5534 & -0.0914 \\
\hline & & Control & 3.718 & 0.000 & 2.9876 & 4.4496 \\
\hline & DM-L ${ }^{0}$ & DM-L & 0.822 & 0.023 & 0.0914 & 1.5534 \\
\hline & & Control & 4.541 & 0.000 & 3.8100 & 5.2720 \\
\hline & Control & DM-L & -3.718 & 0.000 & -4.4496 & -2.9876 \\
\hline & & DM-L ${ }^{0}$ & -4.541 & 0.000 & -5.2720 & -3.8100 \\
\hline
\end{tabular}

The mean difference is significant at the 0.05 level 
Table 6: Correlation of glycemic control and Apolipoprotein B in the diabetic groups

\begin{tabular}{lll}
\hline & r & p \\
\hline HbA1c \& Apo B in DML & 0.277 & 0.052 \\
HbA1c \& Apo B in DML $^{0}$ & 0.422 & 0.002 \\
\hline
\end{tabular}

DM-L - Diabetics on lipid lowering agent,

DM- $\mathrm{L}^{0}$ - Diabetics not on lipid lowering agent,

Apo B - Apolipoprotein B.

Table 7: Relationship between degree of glycaemic control and lipid profile parameters

\begin{tabular}{llllll}
\hline & & $\begin{array}{l}\text { DM-L } \\
\text { n=50 }\end{array}$ & \multicolumn{3}{c}{$\begin{array}{l}\text { DM-L } \\
\mathbf{n = 5 0}\end{array}$} \\
\hline Independent Variable & Dependent Variables & $\mathbf{r}$ & $\mathbf{p}$ & $\mathbf{r}$ & $\mathbf{P}$ \\
\hline HBA1c & TC $(\mathrm{mg} / \mathrm{dl})$ & 0.119 & 0.410 & -0.013 & 0.927 \\
& LDL-C (mg/dl) & -0.024 & 0.870 & 0.166 & 0.250 \\
& HDL-C (mg/dl) & 0.103 & 0.478 & -0.174 & 0.228 \\
& TG (mg/dl) & -0.015 & 0.919 & 0.022 & 0.880 \\
\hline
\end{tabular}

DM-L - Diabetics on lipid lowering agent, DM-L ${ }^{0}-$ Diabetics not on lipid lowering agent,

TC - Total Cholesterol, LDL - Low Density Lipoprotein, HDL - High Density Lipoprotein,

TG - Triglycerides, HBA1c - Glycosylated Hemoglobin

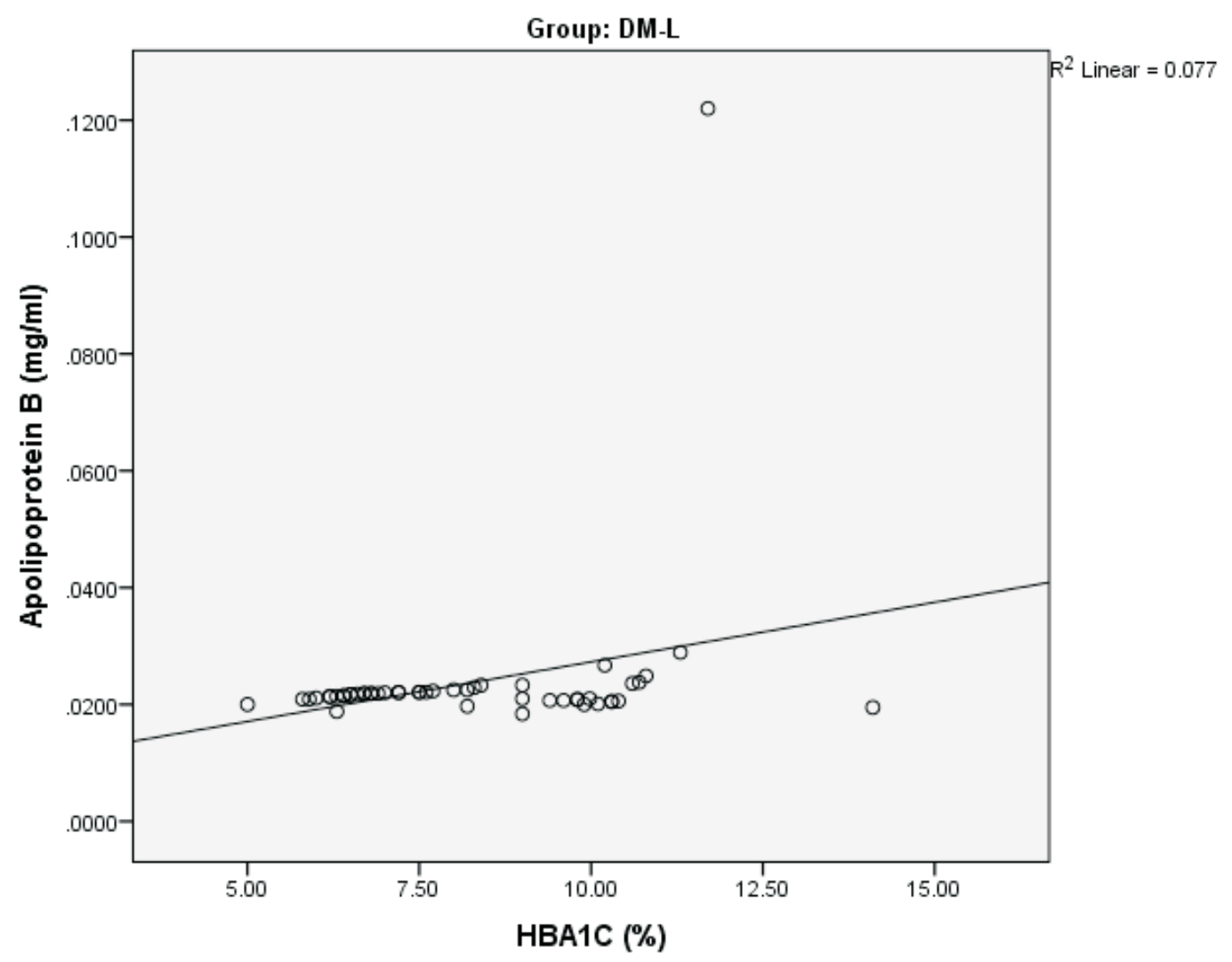

Figure 1: Scatter plot of Apolipoprotein B and HBA1c in Diabetics on lipid lowering agents 


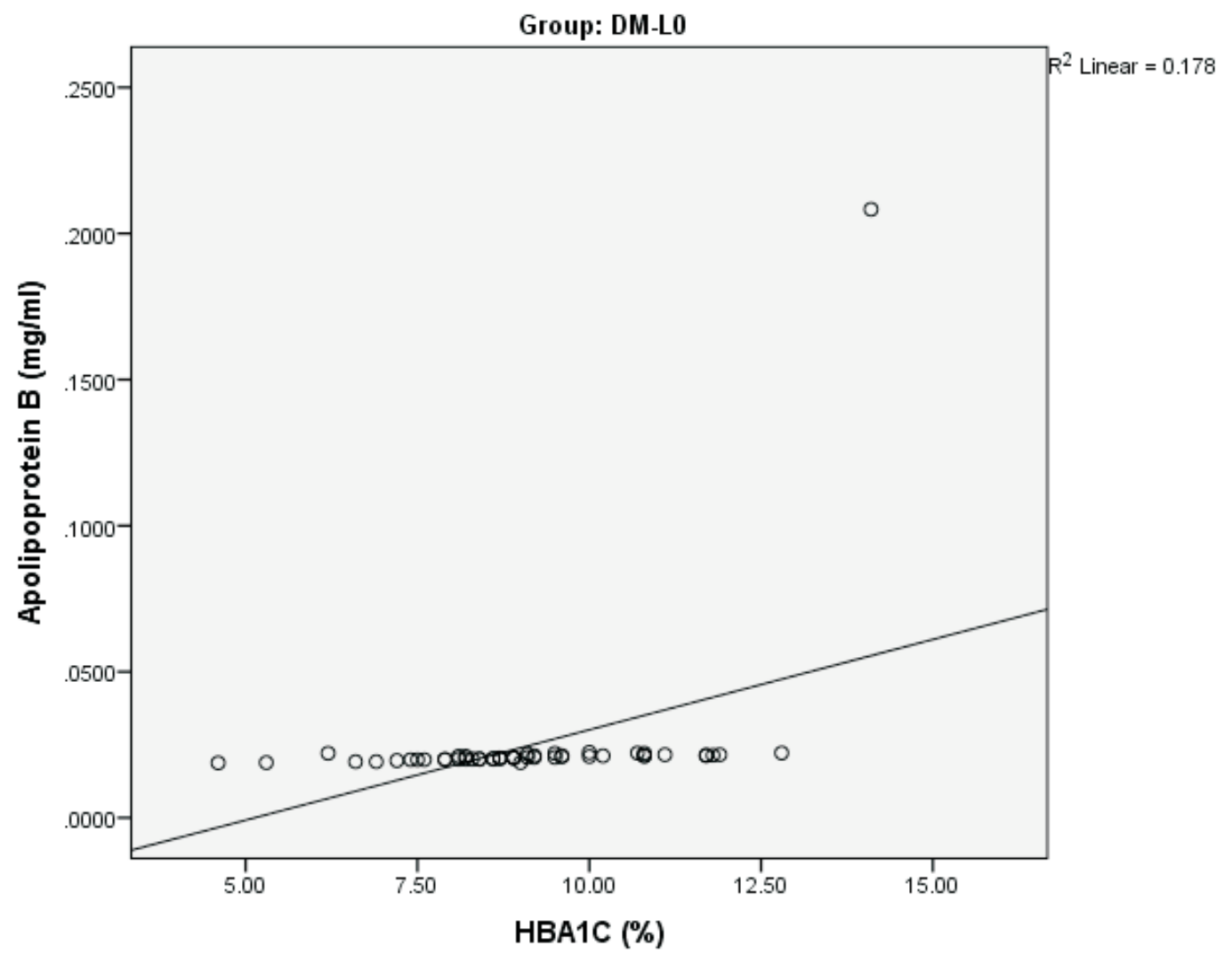

Figure 2: Scatter plot of Apolipoprotein B and HBA1c in Diabetics not on lipid lowering agents 